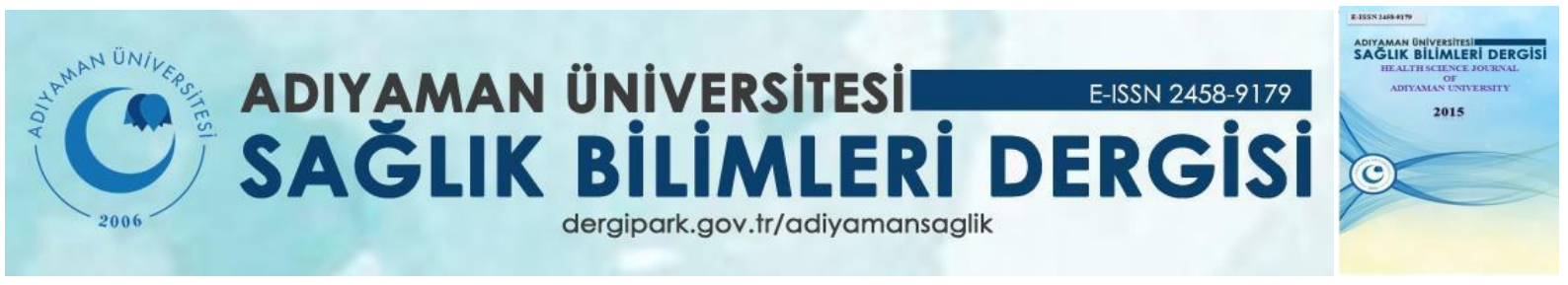

Araştırma/Research

\title{
Görsel Medyanın Oral Cerrahi Öncesi ve Sonrası Anksiyete Üzerine Etkilerinin Değerlendirilmesi
}

\begin{abstract}
Ahmet Taylan ÇEBí1
${ }^{1}$ Karabük Üniversitesi Diş Hekimliği Fakültesi, Ağız, Diş ve Çene Cerrahisi Anabilim Dalı, Karabük, Türkiye, ahmettaylancebi@karabuk.edu.tr / ORCID ID: 0000-0001-9083-7215
\end{abstract}

ÖZ

Amaç: Oral cerrahi işlem planlanan hastalarda yazılı ve sözlü bilgilendirmenin ve görsel medyanın preoperatif ve postoperatif anksiyete üzerine etkilerinin değerlendirilmesi amaçlanmıştır.

Yöntem: Kliniğimize başvuran oral cerrahi yapılmasına karar verilen 100 hasta çalışmaya dahil edildi. Hastalar cerrahi öncesinde ilk olarak standart yazılı aydınlatma formu ve sözlü olarak, daha sonrasında ise video gösterimi ile görsel olarak bilgilendirildi. Preoperatif ve postoperatif olarak tüm hastaların anksiyete düzeyleri State Trait Anxiety Inventory (STAI) kullanılarak belirlendi. Sosyodemografik veriler kaydedildi.

Bulgular: Tüm hastalarda postoperatif anksiyete değerlerinin preoperatif anksiyete değerlerine göre daha düşük olduğu tespit edildi. Yazılı-sözlü ve görsel bilgilendirme sonrasındaki anksiyete seviyelerinin karşılaştırılmasında ise görsel bilgilendirme sonrasında anksiyete seviyesinde anlamlı düzeyde bir artış olduğu gözlendi. Kadın ve erkek hastaların preoperatif ve postoperatif anksiyete düzeyleri arasında herhangi bir fark saptanmadi.

Sonuç: Oral cerrahi işlem öncesinde video ile yapılan görsel bilgilendirmenin preoperatif anksiyete seviyesini önemli düzeyde arttırdığı sonucuna vardık.

Anahtar kelimeler: Anksiyete; oral cerrahi; preoperatif dönem; postoperatif dönem

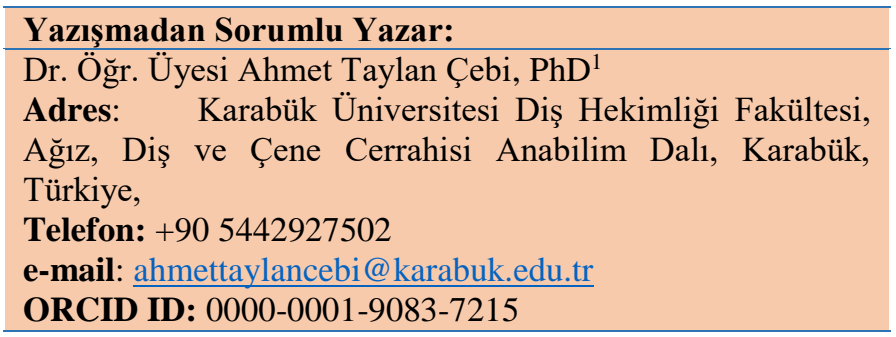

Doi: 10.30569.adiyamansaglik.583841

Geliş Tarihi : 28.06.2019

Kabul Tarihi : 26.11.2019

Atıf Gösterimi/How to Cite: Çebi AT. Görsel Medyanın Oral Cerrahi Öncesi ve Sonrası Anksiyete Üzerine Etkilerinin Değerlendirilmesi. Adıyaman Üni. Sağlık Bilimleri Derg. 2019; 5(3);1746-1756. doi: 10.30569.adiyamansaglik.583841 


\title{
Evaluation Of Effects Of Visual Media On Anxiety Levels Before and After Oral Surgery
}

\begin{abstract}
Objective: The aim of this study was to evaluate the effects of written and verbal information and visual media on preoperative and postoperative anxiety in the patients who were planned for oral surgery.
\end{abstract}

Methods: A hundred patients who were referred to our clinic for oral surgery were included in the study. Patients were informed firstly by a standard written information form and verbal information, and then visually informed by a video demonstration. The anxiety levels of all patients preoperatively and postoperatively were determined using the State Trait Anxiety Inventory (STAI). Sociodemographic data were recorded.

Results: Postoperative anxiety was lower in all patients than in preoperative anxiety. When comparing the levels of anxiety after verbal-written and visual information, it was found that there was a significant increase in the level of anxiety after visual information. There was no difference between preoperative and postoperative anxiety levels of male and female patients.

Conclusion: We concluded that visual information with video before oral surgery significantly increased preoperative anxiety level.

Key words: Anxiety; oral surgery; preoperative period; postoperative period

\section{GíRIŞ}

Anksiyete, kişinin tehlike içeren durumlara karşı otonom sinir sisteminin etkisiyle oluşturduğu stres, endişe, kaygı ve sinirlilik gibi duygusal reaksiyonların bütünü olarak nitelendirilir. Genel olarak cerrahi girişimlerde olduğu gibi minör konservatif dental işlemlerde ve oral cerrahi girişimlerde de anksiyete semptomları görülebilir $(1,2)$. Diğer dental tedavi işlemleriyle karşılaştırıldığında, ağız içi cerrahi girişimlerin hastalar için daha büyük derecede kaygı nedeni olduğu bildirilmiştir (3). Dental anksiyete; hastanın kişilik özelliği, yaşı, cinsiyeti, eğitim durumu ve yaşanmış bir travmatik dental tedavi hikayesi gibi birçok farklı olgudan etkilenen bir duygu durumudur (4). Dental anksiyete, bireylerin dental tedavilerinin tamamlanmasina engel olabilir, tedavi sirasında hastaların daha az koopere olmasına sebebiyet verebilir ve cerrahi işlemlerden hastaların kaçınmasına ve yapılan cerrahiler sonucunda da memnuniyetsizliğe sebep olabilir (5). 
Cerrahi operasyon öncesi hastalarda sıklıkla karşılaşılabilen preoperatif anksiyete; yapılacak olan cerrahiyi, uygulanacak anesteziyi ve postoperatif dönemdeki iyileşme periyodunu olumsuz yönde etkilemektedir (6). Meydana gelen bu preoperatif anksiyete, senkop, hipertansiyon, disritmi, kusma ve baş dönmesi gibi patofizyolojik durumlara ve hatta hastanın yapılacak olan cerrahiden vazgeçmesine sebebiyet verebilir (7). Cerrahi öncesi meydana gelebilen bu anksiyetenin sebepleri içerisinde; bireyin uygulanacak cerrahi işlem ve anestezi tekniği hakkında bilgi sahibi olmaması, operasyon esnasında ve sonrasında ağrı hissetme korkusu, cerrahi işlem sonrasında meydana gelebilecek komplikasyonların endişesi, günlük sosyal yaşantısının bozulması, ameliyathane ortamında yalnız kalması, yakınlarından uzaklaşması say1labilir (8).

Hastanın cerrahi işlem öncesi oluşan anksiyetesini azaltmak, hastayı psikolojik olarak rahatlatmak için birçok preoperatif bilgilendirme metotları kullanılmaktadır (9). Preoperatif bilgilendirmede en fazla kullanılan teknikler yazılı ve sözel bilgilendirme formlarıdır, ancak hastalar içerisinde okur-yazar olmayanlar, verilen bilgileri anlayamayanlar ya da bu bilgileri akılda tutamayanlar olabilir. Bu olumsuzluklarda bu yolların eksikliklerini oluşturmaktadır (10). Bazı çalışmalar sonucunda da yazılı ve sözel bilgilendirmenin yerine görsel içerikli (uygulanacak olan anestezi tekniğinin ve cerrahi işlemin video ile gösterimi gibi) preoperatif bilgilendirmenin hastaların yapılacak olan cerrahi işlem hakkında detaylı bilgi sahibi olmaları ve anksiyete açısından daha verimli olacağı bildirilmiştir (11).

$\mathrm{Bu}$ çalışmanın amacı, oral cerrahi işlem yapılması planlanan hastalarda yazılı ve sözlü bilgilendirme ile ilgili cerrahi işlemin görselleri bulunan bir video sunum bilgilendirmenin preoperatif ve postoperatif anksiyete üzerine etkilerinin karşılaştırılmasıdır.

\section{GEREÇ VE YÖNTEMLER}

Çalışmaya, Karabük Üniversitesi Girişimsel Olmayan Klinik Araştırmalar Etik Kurulu'ndan 13.12.2018 tarihli ve 13/1 karar nolu etik onay alındıktan sonra başlanmış ve çalışmaya katılan tüm hastalara ayrıntılı bilgi verilmiş, onam formu imzalattırılmıştır. Bu çalışma, Helsinki İnsan Hakları Bildirisi ile ilgili kılavuz ilkelere uygun olarak yürütülmüştür. Araştırma, Karabük Üniversitesi Ağız, Diş ve Çene Cerrahisi Anabilim Dalı kliniğine başvuran, lokal anestezi altında oral cerrahi tedavisi yapılması uygun görülmüş (gömülü diş çekimi, apikal rezeksiyon, kist enükleasyonu ve yumuşak doku cerrahisi), 18-57 yaş arası toplam 100 hasta (41 erkek, 59 kadın) üzerinde gerçekleştirilmiştir. Çalışmaya dahil edilmeme kriterleri; 18 yaşından küçük olma, tanısı koyulmuş ve tedavi altında olunan psikolojik ve nörolojik bir hastalığın olması, 
hastaların gönüllü olarak çalışmaya katılmak istememeleri, okur-yazarlığın olmaması, görme ve işitme problemi olması olarak belirlenmiştir.

Hastaların, cinsiyet ve yaş gibi sosyodemografik özellikleri kaydedilmiştir. Hastaların preoperatif ve postoperatif anksiyete seviyeleri Süreksiz Durumluk/Sürekli Kaygı ölçeğinin (State Trait Anxiety Inventory-STAI) anlık (süreksiz) durumluk kaygı envanteri kısmı kullanılarak değerlendirilmiştir (12). Bu kaygı ölçeği, sürekli ve durumluluk kaygıyı değerlendirmek üzere tasarlanmış 20'şer adet ifade içeren iki kısımdan oluşmaktadır. Sürekli kaygı durumunu ölçen kısım, son bir haftada bireyin hissettiklerini ölçmeye yardımcı olurken, durumluk kaygı kısmı ise bireyin o anlık hissettiklerini ölçmek üzere planlanmıştır. Bireylerden, anketteki ifadelerden; 'kesinlikle hiç', 'bazen', 'sıklıkla' ya da 'hemen her zaman' kendilerine en uygun bulduklarını seçmeleri istenmiştir. Ankette yer alan 3, 4, 6, 7, 9, 12, 13, 14, 17, 18. maddelerdeki ifadeler için pozitif, 1, 2, 5, 8, 10, 11, 15, 16, 19 ve 20. maddelerdeki ifadeler için negatif puanlar verilmiştir. Puanlamalar yapılırken değerlendirilen ifadeler için ifadenin pozitif ya da negatif olmasına göre 1 (ya da-1) ile 4 (ya da -4) arasında puan verilmiş ve toplama 50 puan eklenmiştir. Buna göre; 80 en yüksek, 20 ise en düşük puan olarak kabul edilmiştir.

Çalışmamız tek gruptan oluşmaktadır. Hastaların detaylı olarak radyolojik ve klinik muayeneleri yapıldıktan sonra cerrahi operasyon endikasyonu koyulmuştur. Cerrahi yapılmasını kabul eden hastalara ilk olarak yapılacak olan cerrahi işlem ve uygulanacak olan anestezi hakkında yazılı ve sözlü bilgilendirme yapılmış ve hemen akabinde preoperatif olarak STAI kaygı envanteri kullanılarak değerlendirme yapılmıştır. Daha sonrasında hastalara 60 dakika kadar bir dinlenme süresi tanınmıştır. 60 dakikalık dinlenme periyodu sonrasında hastalara yapılacak olan operasyonların ilgili video gösterimleri yapılmış (anestezi tekniğini ve yapılacak olan cerrahi işlemin basamaklarını gösteren operasyonun süre olarak da simüle eden video sunumlar) ve bu video gösterimlerin hemen akabinde preoperatif olarak STAI kayg1 envanteri kullanılarak değerlendirme yapılmıştır. Daha sonra hastaların ameliyat randevuları verilmiş, ilgili operasyon gününde cerrahi müdahale uygulandıktan sonra da tekrar STAI kayg1 envanteri kullanılarak değerlendirme yapılmıştır.

Elde edilen veriler Minitab 17 istatistiksel veri analiz programı ile değerlendirilmiştir. İstatistiksel verilerin incelenmesinde tanımlayıcı istatistiksel analizler (ortalama, standart sapma, frekans) kullanılmıştır. Verilerin normal dağılıma uygun olup olmadığı Shapiro-Wilk testi kullanılarak belirenmiş ve sonuçlar \%95 güven aralığında değerlendirilmiştir. Parametrik 
verilerin iki grup arası karşılaştırmalarında Student t-test, parametrik olmayan verilerin iki grup arası karşılaştırmalarında ise Mann-Whitney $U$ testi kullanılmıştır. Tüm analizlerin sonuçları anlamlılık $\mathrm{p}<0.05$ ve $\mathrm{p}<0.001$ olarak değerlendirilmiştir

\section{BULGULAR}

Çalışmaya, yaşları 18 ile 57 arasında değişen 41 erkek ve 59 kadın olmak üzere 100 hasta dahil edilmiştir. Çalışmamıza dahil edilen ve oral cerrahi işlem gören hastaların yaş ortalaması 27,62 \pm 9,06 olarak bulunmuştur. Kadın ve erkek hastaların yaş ortalamaları arasındaki fark istatistiksel olarak anlamlı bulunmuştur $(\mathrm{p}=0,041)$ (Tablo I).

Tablo I: Demografik özelliklerin değerlendirilmesi

\begin{tabular}{|l|c|c|c|c|}
\hline & $\mathbf{n}$ & \% & Yaş ortalaması & $\mathbf{p}$ \\
\hline Kadın & 59 & $\% 59$ & $26 \pm 7,83$ & $0,041^{*}$ \\
\hline Erkek & 41 & $\% 41$ & $29,95 \pm 10,2$ & \\
\hline
\end{tabular}

$$
* \mathrm{p}<0,05
$$

Erkek hastalarda preoperatif video gösterimli bilgilendirme sonrasındaki anksiyete değer ölçümleri, sözlü ve yazılı bilgilendirme sonrasındaki anksiyete değerlerine göre istatistiksel olarak anlamlı düzeyde yüksek bulunmuştur $(\mathrm{p}=0,009)$ (Tablo II). Kadın hastalarda preoperatif video gösterimli bilgilendirme sonrasındaki anksiyete değerleri, sözlü ve yazılı bilgilendirme sonrasındaki anksiyete değerlerine göre istatistiksel olarak anlamlı düzeyde yüksek bulunmuştur $(\mathrm{p}<0,001)$ (Tablo II). Çalışmaya katılan tüm hastalarda, preoperatif video gösterimli bilgilendirme sonrasındaki anksiyete değerleri, sözlü ve yazılı bilgilendirme sonrasındaki anksiyete değerlerine göre istatistiksel olarak anlamlı düzeyde yüksek bulunmuştur $(\mathrm{p}<0,001)$ (Tablo II).

Tablo II: Preoperatif STAI skorlaması sonuçları

\begin{tabular}{|l|c|c|c|}
\hline STAI Skorlaması & $\begin{array}{c}\text { Yazılı-sözlü } \\
\text { bilgilendirme }\end{array}$ & Görsel bilgilendirme & $\mathbf{p}$ \\
\hline Kadın & $48,29 \pm 14,15$ & $54,69 \pm 14,47$ & $0,000^{* *}$ \\
\hline Erkek & $47,66 \pm 12,60$ & $52,76 \pm 11,62$ & $0,009 *$ \\
\hline Toplam & $48,17 \pm 13,40$ & $53,86 \pm 13,40$ & $0,000^{* *}$ \\
\hline
\end{tabular}

$* \mathrm{p}<0,05 * * \mathrm{p}<0,001$ Student $\mathrm{t}$ testi 
Erkek, kadın ve tüm hastaların preoperatif sözlü-yazılı ve video gösterimli bilgilendirme sonrasındaki anksiyete seviyeleri, postoperatif anksiyete seviyelerinden istatistiksel olarak anlamlı düzeyde yüksek bulunmuştur ( $\mathrm{p}<0,001)$ (Tablo III).

Tablo III: Preoperatif ve postoperatif STAI skorları değerlendirilmesi

\begin{tabular}{|c|c|c|c|}
\hline STAI skorlaması & Ortalama & Standart sapma & $\mathbf{p}$ \\
\hline $\begin{array}{l}\text { Preoperatif sözlü-yazılı bilgilendirme } \\
\text { erkek hasta anksiyete değerleri }\end{array}$ & 47,66 & 12,60 & $0,000 * *$ \\
\hline $\begin{array}{l}\text { Postoperatif erkek hasta anksiyete } \\
\text { değerleri }\end{array}$ & 35,0 & 9,98 & \\
\hline $\begin{array}{l}\text { Preoperatif görsel bilgilendirme erkek } \\
\text { hasta anksiyete değerleri }\end{array}$ & 52,76 & 11,62 & $0,000 * *$ \\
\hline $\begin{array}{l}\text { Postoperatif erkek hasta anksiyete } \\
\text { değerleri }\end{array}$ & 35,0 & 9,98 & \\
\hline $\begin{array}{l}\text { Preoperatif sözlü-yazılı bilgilendirme } \\
\text { kadın hasta anksiyete değerleri }\end{array}$ & 48,29 & 14,15 & $0,000 * *$ \\
\hline $\begin{array}{l}\text { Postoperatif kadın hasta anksiyete } \\
\text { değerleri }\end{array}$ & 34,07 & 7,94 & \\
\hline $\begin{array}{l}\text { Preoperatif görsel bilgilendirme kadın } \\
\text { hasta anksiyete değerleri }\end{array}$ & 54,69 & 14,47 & $0,000 * *$ \\
\hline $\begin{array}{l}\text { Postoperatif kadın hasta anksiyete } \\
\text { değerleri }\end{array}$ & 34,07 & 7,94 & \\
\hline $\begin{array}{l}\text { Preoperatif sözlü-yazılı bilgilendirme } \\
\text { toplam hasta anksiyete değerleri }\end{array}$ & 48,77 & 13,40 & $0,000 * *$ \\
\hline $\begin{array}{l}\text { Postoperatif toplam hasta anksiyete } \\
\text { değerleri }\end{array}$ & 34,45 & 8,80 & \\
\hline $\begin{array}{l}\text { Preoperatif görsel bilgilendirme toplam } \\
\text { hasta anksiyete değerleri }\end{array}$ & 53,86 & 13,40 & $0,000 * *$ \\
\hline $\begin{array}{l}\text { Postoperatif toplam hasta anksiyete } \\
\text { değerleri }\end{array}$ & 34,45 & 8,80 & \\
\hline
\end{tabular}
$* * p<0,001$ Mann Whitney U testi

Erkek hastaların preoperatif sözlü ve yazılı bilgilendirme sonrasındaki anksiyete ölçümleri ile kadın hastaların preoperatif sözlü ve yazılı bilgilendirme sonrasındaki anksiyete ölçümleri arasında istatistiksel olarak anlamlı bir fark bulunmamıştır ( $p=0,914)$ (Tablo IV). 
Tablo IV: Kadın ve erkek hasta STAI skorları değerlendirmesi

\begin{tabular}{|l|c|c|c|}
\hline & Ortalama & $\begin{array}{c}\text { Standart } \\
\text { sapma }\end{array}$ & p \\
\hline $\begin{array}{l}\text { Preoperatif sözlü-yazılı bilgilendirme } \\
\text { erkek hasta anksiyete değerleri }\end{array}$ & 47,66 & 12,60 & 0,914 \\
\hline $\begin{array}{l}\text { Preoperatif sözlü-yazılı bilgilendirme } \\
\text { kadın hasta anksiyete değerleri }\end{array}$ & 48,29 & 14,15 & \\
\hline & & & 0,441 \\
\hline $\begin{array}{l}\text { Preoperatif görsel bilgilendirme erkek } \\
\text { hasta anksiyete değerleri }\end{array}$ & 52,76 & 11,62 & \\
\hline $\begin{array}{l}\text { Preoperatif görsel bilgilendirme kadın } \\
\text { hasta anksiyete değerleri }\end{array}$ & 54,69 & 14,47 & 0,62 \\
\hline $\begin{array}{l}\text { Postoperatif erkek hasta anksiyete } \\
\text { değerleri }\end{array}$ & 35,0 & 9,98 & \\
\hline $\begin{array}{l}\text { Postoperatif kadın hasta anksiyete } \\
\text { değerleri }\end{array}$ & 34,07 & 7,94 & \\
\hline
\end{tabular}

Mann Whitney U testi

Erkek hastaların preoperatif video gösterimli bilgilendirme sonrasındaki anksiyete ölçümleri ile kadın hastaların preoperatif video gösterimli bilgilendirme sonrasındaki anksiyete ölçümleri arasında istatistiksel olarak anlamlı bir fark bulunmamıştır $(\mathrm{p}=0,441)$ (Tablo IV).

Erkek ve kadın hastaların postoperatif anksiyete düzeyleri arasında istatistiksel olarak herhangi bir fark bulunmamıştır $(\mathrm{p}=0,62)$ (Tablo IV).

\section{TARTIŞMA}

Preoperatif dönemde, hastada yapılacak olan cerrahi işleme ve bu cerrahi işlem için uygulanacak anestezi metoduna bağlı olarak oluşan endişe ve korkunun kişinin anksiyete düzeyini etkilediği bilinmektedir. Mevcut olan bu preoperatif anksiyetenin de cerrahi işlemin başarısını, hastaların memnuniyet düzeylerini olumsuz yönde etkilediği gösterilmiştir. $\mathrm{Bu}$ nedenle preoperatif anksiyeteyi en aza indirgemeye yönelik uygulanabilecek yöntemlerin, metodların araştırılması giderek fazlalaşmaktadır (13). Ng ve ark., preoperatif olarak yapılması planlanan cerrahi işlem ve uygulanacak olan anestezi tekniği ya da teknikleri hakkında bilgilendirme yapılmasının hastaların anksiyete seviyelerini düşürmede etkili olduğunu bildirmişlerdir (14). Bizim çalışmamızda da; preoperatif olarak video gösterimli bir görsel bilgilendirme ve yazıl1-sözlü bilgilendirme yöntemleri kullanılmıştır ve preoperatif uygulanan yazıl1-sözlü bilgilendirmenin, video gösterimli görsel bilgilendirmeye göre anksiyete seviyesini daha çok düşürdüğü sonucuna varılmıştır. 
Literatürde oral cerrahi işlemler öncesi ve sonrası anksiyete değerlendirmesi yapılan birçok çalışmada anksiyete ölçümleri için STAI kaygı envanteri kullanılmıştır (15-17). Bu bilgiyle paralel olarak; bizim çalışmamızda da, hastaların preoperatif ve postoperatif anksiyete seviyelerinin değerlendirilmesinde STAI kaygı envanteri kullanılmıştır.

Jlala ve arkadaşları, rejyonal anestezi uygulanarak yapılacak olan alt ve üst ekstremite cerrahisi hastaları üzerinde yaptıkları çalışmalarında, hastalara uygulanacak olan anestezi tekniğini anlatan kısa bir video gösterisi ile preoperatif bilgilendirme yapmışlardır. Preoperatif 2 hafta önce yaptıkları anksiyete değerlendirmesinde hastaların \%17'sinde yüksek anksiyete skoru bulmuşlar, cerrahi işlemden hemen önce ise bu oran, video gösterimini izleyen grupta \%27'ye, izlemeyenlerde ise \%36’ya yükselmiştir. Preoperatif olarak uygulanan video aracıllı̆̆ıla uygulanan görsel bilgilendirmenin, rejyonal anestezi uygulanarak cerrahi yapılacak olan hastaların anksiyetesini azalttığını ve bu tür bilgilendirmenin uygulanabilirliğinin kolay olduğunu vurgulamışlardır (8). Coşkun Türer ve Durmuş ise çalışmalarında görsel ve yazılı bilgilendirmenin periodontal cerrahi öncesi ve sonrası anksiyete düzeyine etkilerine bakmış olup çalışmaya 200 hasta dahil etmişlerdir. Görsel bilgilendirme aracı olarak resimli bir katalog kullanmışlardır. Araştırmalarının sonuçlarına göre ise; görsel olarak preoperatif bilgilendirme yaptıkları hasta grubunda anksiyete seviyelerinin daha düşük olduğunu ve her iki grupta da postoperatif anksiyete seviyelerinin preoperatif anksiyete seviyelerine göre daha düşük olduğunu tespit etmişlerdir (18). Spinal anestezi uygulanarak cerrahi yapılacak olan 18-65 yaş arası 210 hastada yapılan bir çalışmada da; hastalar 2 gruba ayrılmış ve bir gruba preoperatif olarak spinal anestezi yönteminin uygulanma resimleri bulunan bir katalog ile görsel bilgilendirme yapılmış, diğer gruba ise geleneksel bir yöntem olan yazılı bilgilendirme yapılmıştır. Çalışma sonuçlarına göre yazarlar, görsel bilgilendirme yönteminin anksiyete seviyesini daha yüksek oran da düşürdüğünü bildirmişlerdir (11). Kazancıoğlu ve ark. üçüncü molar diş cerrahisi yapacakları 333 hastayı çalışmalarına dahil etmişler ve 3 grup oluşturmuşlardır. 1. gruba preoperatif olarak sözel bilgilendirme yapmışlar, 2.gruba yani çalışma grubuna hem sözel bilgilendirme hem de 5 dakikalık video gösterimi ile görsel bir preoperatif bilgilendirme yapmışlar, 3.grup olan kontrol grubuna ise ameliyat prosedürlerini ve iyileşme periyodu hakkında bilgi içermeyen genel bir bilgilendirme yapmışlardır. Çalışmaları sonucunda, video gösterim ile preoperatif bilgilendirme yaptıkları gruptaki hastaların preoperatif anksiyete seviyelerini diğer hasta gruplarına göre yüksek olarak bulmuşlar ve video gösterim sonrasında bu gruptaki hastaların anksiyete seviyelerinde azalma tespit etmişlerdir (19). Bizim çalışmamızda ise; lokal anestezi altında oral cerrahi işlem uygulanan 100 hasta 
çalışmaya dahil edilmiş, hastalara yapılacak olan cerrahi işlem ve uygulanacak olan anestezi ile ilgili preoperatif olarak hem yazılı ve sözlü bilgilendirme hem de video gösterimi ile yapılan görsel bir bilgilendirme yapılmıştır. Bizim çalışmamızın sonucunda ise bu çalışmaların sonuçlarından farklı olarak bir sonuç bulunmuş; video gösterimi ile yapılan preoperatif bilgilendirme sonucunda hastaların anksiyete seviyelerinin daha fazla arttığı tespit edilmiştir. $\mathrm{Bu}$ farklılığın sebeplerini ise, hastalara izletilen videoların uygulanacak olan cerrahi işlem ve anestezi tekniğini birebir hem yöntem olarak hem de süre olarak simüle etmesine, çalışmaya dahil edilen hastaların yaş sınırlamalarının farklı olmasına ve hastaların yapılacak olan cerrahi işlemi sözel ve yazılı bilgilendirmede sonucunda tam anlayamamalarına ve zihinlerinde tam canlandıramamalarına bağlamaktayız.

Cerrahi işlemler öncesi hastalarda oluşan preoperatif anksiyetenin en önemli nedeni uygulanacak olan cerrahinin ağrı yaratacağı korkusudur. Postoperatif anksiyete seviyelerinin düşmesinin sebebi ise hastaların cerrahi işlem sırasında ve sonrasında hissedeceklerini düşündükleri ağrı seviyelerinin ve postoperatif konfor düzeylerinin düşündükleri gibi olmadıklarını görmeleridir (20). Dental fobisi olan ve olmayan hastaların kıyaslanmasının yapıldığı bir çalışmada da, hastaların cerrahi işlem sonrası anksiyete seviyeleri, cerrahi işlem öncesine göre düşük olarak tespit edilmiştir (21). Bizim çalışmamızda da literatür ile uyumlu olarak, oral cerrahi işlem uygulanan tüm hastaların postoperatif anksiyete değerleri preoperatif anksiyete değerlerinden daha düşük bulunmuştur.

Sağır ve ark. (11), Kazancıoğlu ve ark. (19) ve Lemonnier ve ark. (22) çalışmaları sonucunda kadın hastaların erkek hastalara oranla anksiyete seviyelerinin daha yüksek olduğunu bildirirken, Pani ve ark. (23), Liu ve ark. (24) ve Lalabonova ve ark. (25) ise cinsiyetin anksiyete üzerine etkisini değerlendirdikleri çalışmalarında kadın ve erkek hastaların anksiyete seviyeleri arasında herhangi bir fark tespit etmemişlerdir. Bizim çalışmamızın sonucunda da cerrahi öncesi yazılı ve sözlü bilgilendirme ile video gösterimli görsel bilgilendirme yapılan kadın ve erkek hastalarda preoperatif ve postoperatif anksiyete ölçümleri değerlendirilmesinde herhangi bir fark tespit edilmemiştir.

\section{SONUÇ}

Değerlendirme yöntemlerinin farklılığına rağmen preoperatif anksiyete seviyelerinin postoperatif anksiyete seviyelerine göre yüksek olduğu görülmektedir. Çalışmamızda video aracılığıyla yapılan görsel preoperatif bilgilendirmenin yazılı ve sözlü bilgilendirmeye göre hastalar üzerinden daha çok korku ve endişe uyandırdığı sonucuna varılmış, yapılacak cerrahi 
işlemin basamaklarını görmenin, izlemenin hastalarda anksiyete seviyesini arttırdığı tespit edilmiştir. Hastaların uygulanacak olan tedaviler öncesinde preoperatif bilgilendirilmelerinin hasta-hekim ilişkisinde etik bir yaklaşım olduğunu ve hasta kooperasyonunda daha etkili olduğunu düşünmekteyiz.

\section{KAYNAKLAR}

1. De Jongh A, Adair P, Meijerink-Anderson M. Clinical management of dental anxiety: what works for whom? International dental journal 2005;(55):73-80.

2. Newton JT. Anxiety and pain measures in dentistry: a guide to their quality and application. J Am Dent Assoc 2000;(131):1449-1457.

3. Ekanayake L, Dharmawardena D. Dental anxiety in patients seeking care at the University Dental hospital in Sri Lanka. Community Dent Health 2003;20:112-116.

4. Locker D, Thomson W.M, Poulton R. Psychological disorder, conditioning experiences, and the onset of dental anxiety in early adulthood. J Dent Res 2001;80:1588-1592.

5. González-Lemonnier S, Bovaira-Forner M, Peñarrocha- Diago M, Peñarrocha-Oltra D. Relationship between preoperative anxiety and postoperative satisfaction in dental implant surgery with intra venous conscious sedation. Med Oral Patol Oral Cir Bucal 2010;15:379-82.

6. Caumo W, Schmidt AP, Schneider CN, Bergmann J, Iwamoto CW, Adamatti LC, Bandeira D, Ferreira MBC. Risk factors for postoperative anxiety in adults. Anaesthesia 2001;56:720-8.

7. McCleane GJ, Cooper R. The nature of pre-operative anxiety. Anaesthesia 1990;45:153-5.

8. Jlala HA, French JL, Foxall GL, Hardman JG, Bedforth NM. Effect of preoperative multimedia information on periopoerative anxiety in patients undergoing procedures under regional anaesthesia. $\mathrm{Br}$ J Anaesth 2010;104:369-74.

9. Ong CK, Seymour RA, Tan JM. Sedation with midazolam leads to reduced pain after dental surgery. Anesth Analg 2004;98:1289-93.

10. Stanley BM, Walters DJ, Maddern GJ. Informed consent: how much information is enough? Aust N Z J Surg 1998;68:788-91.

11. Sağır G, Kaya M, Eskiçırak HE, Kapusuz Ö, Kadıogulları AN. Spinal anestezi planlanan hastalarda görsel bilgilendirmenin preoperatif anksiyete üzerine etkisi. Turk J Anesth Reanim 2012;40:274-8.

12. Spielberger CD, Gorsuch RL, Lushene RE, Vagg PR, Jacobs GA. Manual for State and Trait Anxiety Inventory. Consulting Psychologists Press, Palo Alto 1983.

13. Badner NH, Nielson WR, Munk S, Kwiatkowska C, Gelb AW. Preoperative Anxiety: Detection and Contributing Factors. Can J Anaesth 1990;37:444-7.

14. Ng SKS, Chau AWL, Leung WK The effect of preoperative information in relieving anxiety in oral surgery patients. Community Dent Oral Epidemiol 2004;32:227-235.

15. Kazancioglu HO, Dahhan AS, Acar AH. How could multimedia information about dental implant surgery effects patients' anxiety level? Med Oral Patol Oral Cir Bucal 2017;22(1):102-107.

16. Gómez-de Diego R, Soriano AC, Martín JM, Frutos JCP, Valverde AL. State anxiety and depression as factors modulating and influencing postoperative pain in dental implant surgery. A prospective clinical survey. Med Oral Patol Oral Cir Bucal 2014;16(7):592-597. 
17. Candido MC, Andreatini R, Zielak JC, de Souza JF, Losso EM. Assessment of anxiety in patients who undergo surgical procedures for tooth implants: a prospective study. Oral Maxillofac Surg 2015;(19):253258.

18. Ç Coşkun Türer, D Durmuş. Görsel ve Yazılı Bilgilendirmenin Periodontal Cerrahi Öncesi ve Sonrası Anksiyete Seviyelerine Etkisi. Atatürk Üniv. Diş Hek. Fak. Derg. 2017;27(3):167-172.

19. Kazancioglu HO, Tek M, Ezirganli S, Demirtas N. Does Watching a Video on Third Molar Surgery Increase Patient's Anxiety Level. Oral Surg Oral Med Oral Pathol Oral Radiol 2015;119:272-7.

20. Shepherd JP. Strategies for the study of long-term sequelae of oral and facial injuries: Review. J Oral Maxillofac Surg 1992;50(4):390-9.

21. Enkling N, Hardt K, Katsoulis J, Ramseier CA, Colombo A, Jöhren P, Mericske-Stern R. Dental phobia is no contraindication for oral implant therapy. Quintessence Int 2013; 44(4): 363-371.

22. Lemonnier SG, MB Forner, Diago MP, Oltra DP. Relationship between preoperative anxiety and postoperative satisfaction in dental implant surgery with intravenous conscious sedation. Med Oral Patol Oral Cir Bucal 2010;15(2):379-382.

23. Pani SC, AlGarni B, AlZain LM, AlQahtani NS. Assessment of the impact of stress and anxiety on pain perception in patients undergoing surgery for placement of their first dental implant. Oral Health Dent Manag 2014;13(2):464-468. 27.

24. Liu Y, Li B, Wang L, Li C. Preoperative anxiety decrease the postoperative satisfaction in anterior dental implant surgery. Int J Clin Exp Med 2016;9(10):20044-20049.

25. Lalabonova CK. Dental Investigations. Impact Of Dental Anxiety On The Decision To Have Implant Treatment/Влияние Стоматологической Тревожности На Выбор Имплантологического Лечения. Folia medica 2105;57(2):116-121. 